\title{
Modelo de angiogênese inflamatória em córnea de coelho induzida pela cauterização alcalina pontual ${ }^{1}$
}

\author{
Model of inflammatory angiogenesis in rabbit cornea induced by punctual alkaline \\ cauterization
}

\section{Francisco Vagnaldo Fechine-Jamacaru², José Ueides Fechine Júnior ${ }^{3}$, Manoel Odorico de Moraes Filho ${ }^{4}$}

1. Trabalho realizado no Laboratório de Cirurgia Experimental (LABCEX) do Programa de Pós-Graduação Stricto Sensu em Cirurgia, Departamento de Cirurgia, Universidade Federal do Ceará (UFC).

2. Aluno do Programa de Pós-Graduação Stricto Sensu em Cirurgia, nível de Doutorado, do Departamento de Cirurgia da UFC.

3. Aluno do Curso de Medicina da UFC.

4. Professor Adjunto Doutor (PhD) do Departamento de Fisiologia e Farmacologia da UFC.

\section{RESUMO}

Objetivo: Estabelecer um modelo de angiogênese em córnea de coelho, induzida pela cauterização pontual com hidróxido de sódio. Métodos: Seis coelhos foram submetidos a uma cauterização pontual na córnea direita, utilizando-se uma peça circular ( $3 \mathrm{~mm}$ ) de papel filtro, previamente embebida em $\mathrm{NaOH} 1 \mathrm{M}$, a qual foi posicionada a $1 \mathrm{~mm}$ do limbo superior durante 2 minutos. Os animais foram avaliados nos dias 3, 6, 9, 12 , 15, 18 e 21, após a cauterização. A quantificação da angiogênese foi realizada de acordo com 4 métodos: comprimento vascular radial $(\boldsymbol{V})$, índice angiogênico $(\boldsymbol{I})$, área do triângulo $(\boldsymbol{T})$ e do setor de coroa circular (S), ambas medidas aproximadas da área de neovascularização. Resultados: A análise das curvas dos quantificadores revelou que a resposta angiogênica seguiu um padrão bifásico: crescente até o 12odia (proliferação), estável do $12^{\circ}$ ao 21ํ dia (maturação). Comportamento também observado na taxa de crescimento vascular, que foi 16 vezes maior no período de 0 a 12 dias do que no intervalo entre o $12^{\circ}$ e 0 $21^{\circ}$ dia. Foi constatada, ainda, uma correlação linear positiva estatisticamente significante entre os 4 quantificadores de angiogênese. Conclusão: A cauterização alcalina pontual da córnea de coelho induz e mantém neovascularização corneana, podendo, assim, ser utilizada como modelo de angiogênese.

Descritores: Angiogênese. Inflamação. Cauterização alcalina. Córnea. Coelhos.

\begin{abstract}
Purpose: To establish a model of angiogenesis in rabbit cornea induced by punctual alkaline cauterization. Methods: Six rabbits were submitted to punctual cauterization in right cornea. It was used a circular piece (3 $\mathrm{mm}$ ) of filter paper, that was previously soaked in $1 \mathrm{M} \mathrm{NaOH}$ and placed $1 \mathrm{~mm}$ from the superior limbus for 2 minutes. The animals were evaluated at 3, 6, 9, 12, 15, 18 and 21 days after cauterization. Quantification of angiogenesis was performed according to 4 methods: radial vessel length $(\boldsymbol{V})$, angiogenic index $(\boldsymbol{I})$, area of the triangle $(\boldsymbol{T})$ and area of the circular band sector $(\boldsymbol{S})$, which provide an approximation of the area of neovascularization. Results: The analysis of the quantitative data of angiogenesis showed that neovascular response progressed in a biphasic manner: rising between days 0 and 12 (proliferation), stable between days 12 and 21 (maturation). This pattern was observed on the values of the vascular growth mean rate. Between days 0 and 12, it was 16 times greater than that verified between days 12 and 21. It was found a statiscally significant positive linear correlation among the 4 methods of measurement of angiogenesis. Conclusion: The punctual alkaline cauterization of the rabbit cornea induces and sustains corneal neovascularization, so that, it
\end{abstract}


can be used as model of angiogenesis.

Key words: Angiogenesis. Inflammation. Alkaline cauterization. Cornea. Rabbits.

\section{Introdução}

A formação de novos vasos sangüíneos envolve dois processos fundamentais: vasculogênese e angiogênese. Vasculogênese é a formação primária de vasos sangüíneos a partir dos precursores da célula endotelial, os angioblastos, durante o desenvolvimento embrionário. Caracteriza-se pela diferenciação e proliferação dos angioblastos, que se organizam numa rede vascular primitiva, denominada de plexo capilar primário, a partir do qual novos brotos capilares podem germinar, constituindo a base para o processo angiogênico. Angiogênese ou neovascularização é assim definida como o desenvolvimento de novos vasos sangüíneos a partir de capilares pré-existentes ${ }^{1-}$ 3 .

A angiogênese normal ocorre, mormente, durante o desenvolvimento embrionário ${ }^{1}$. É observada, porém, ao longo da vida adulta, em alguns eventos fisiológicos, tais como: ovulação, ciclo endometrial, desenvolvimento da placenta, reparação de feridas ${ }^{2-}$ ${ }^{4}$. Dessa forma, a angiogênese é essencial para o processo de reprodução, desenvolvimento e reparação. Nestas condições, é ativada por um curto período e, a seguir, completamente inibida ${ }^{5}$.

$O$ controle da angiogênese é feito por um fino balanço entre fatores endógenos promotores e inibidores ${ }^{5,6}$. De fato, a célula endotelial do organismo adulto sadio apresenta um turnover muito lento exceto nas situações fisiológicas anteriormente descritas ${ }^{1,6}$. A manutenção da célula endotelial neste estado quiescente é determinada pela ação coordenada de fatores positivos e negativos ${ }^{5}$. Sendo assim, quando os reguladores positivos predominam, a célula endotelial é ativada, prolifera e migra, ao passo que, quando o domínio é dos reguladores negativos, a célula endotelial retorna ao estado quiescente e assim se mantém (angiogenic switch). Evidentemente, a ativação da célula endotelial pode envolver tanto a indução de um fator promotor quanto a perda de um inibidor 6 .

A angiogênese constitui, portanto, um complexo processo, que envolve mediadores solúveis, interações célula-célula e célula-matriz extracelular, bem como forças biomecânicas ${ }^{1}$. Compreende diversas etapas, que, de forma simplificada, podem ser assim descritas: aumento da permeabilidade vascular e deposição de fibrina extravascular; desarranjo da parede vascular, com remoção dos pericitos; degradação da membrana basal e da matriz extracelular; migração da célula endotelial através da matriz extracelular remodelada; proliferação da célula endotelial; formação de estruturas tubulares; inibição da proliferação e migração da célula endotelial; reconstituição da membrana basal; maturação dos complexos juncionais; construção da parede vascular, através do recrutamento e diferenciação de células murais - pericitos e células de músculo liso; estabelecimento de fluxo sangüíneo no novo vaso ${ }^{1,3,6}$.

Quando os mecanismos de controle falham, a angiogênese ${ }^{-}$seja excessiva ou deficiente ${ }^{-}$tornase patológica, dando origem, então, às chamadas doenças angiogênese-dependentes. Na realidade, em quase todas as especialidades médicas pode-se descrever alguma condição associada com a angiogênese. Entre as afecções onde se observa exacerbação do processo angiogênico, podemos citar: artrite reumatóide, psoríase, hemangiomas, retinopatia diabética, degeneração macular relacionada à idade, retinopatia da prematuridade, glaucoma neovascular, oclusão da veia central da retina, neovascularização corneana, rejeição de transplante de córnea, crescimento tumoral e metastático. Outras doenças decorrem, por outro lado, de uma angiogênese insuficiente, entre elas: úlcera gástrica e duodenal, úlceras cutâneas crônicas, isquemia cerebral, miocárdica e periférica ${ }^{2,4,7}$.

Sendo assim, grande esforço tem sido feito com o intuito de desvendar os mecanismos envolvidos no processo angiogênico, bem como descobrir drogas que tenham como alvo tais mecanismos e que possam ser incorporadas ao arsenal terapêutico das doenças angiogênese-dependentes, principalmente o câncer. Para tanto, vários modelos de estudo de angiogênese foram desenvolvidos, tanto in vitro quanto in vivo. De fato, a diversidade de ensaios atualmente em uso tem gerado um sério problema de interpretação da grande variedade de resultados ${ }^{8}$.

Um dos modelos mais utilizados é o ensaio de angiogênese em córneas ${ }^{2}$. Este modelo é considerado 
um dos melhores ensaios in vivo, uma vez que a córnea é uma estrutura avascular, transparente e de fácil acesso e observação, de modo que qualquer vaso sangüíneo que cresça no seu interior decorre do estímulo angiogênico utilizado ${ }^{8,9}$. Tais peculiaridades anatômicas facilitam o monitoramento direto da resposta neovascular, de forma não invasiva, e permitem inclusive a aplicação tópica da droga em teste ${ }^{10}$.

Vários foram, então, os modelos descritos para o estudo de angiogênese em córnea, seja de coelho, rato ou camundongo, nos quais o potencial angiogênico de células e substâncias pôde ser determinado ${ }^{11}$. A técnica mais difundida consiste na confecção de uma microbolsa no estroma corneano ${ }^{9}$, onde podem ser introduzidos fragmentos de tecidos, de natureza neoplásica ou não, suspensões de células $^{8,9}$ ou pellets de liberação lenta, preparados com polímeros inertes, aos quais são incorporados fatores pró-angiogênicos ou drogas antiangiogênicas s,8,9,10,12 $^{2} \mathrm{O}$ implante de pellets de liberação lenta contendo um fator pró-angiogênico provê uma resposta neovascular persistente e agressiva, dependente da estimulação direta pelo fator utilizado e não de estímulos indiretos decorrentes da indução de inflamação $0^{2,10}$. Por outro lado, tal procedimento demanda habilidade técnica e tempo para a sua execução.

Outra técnica bastante utilizada é a indução de angiogênese inflamatória na córnea, seja mediante uma injúria mecânica, térmica ou, mais comumente, uma cauterização química ${ }^{13}$. As substâncias químicas geralmente utilizadas para a realização da cauterização são: o nitrato de prata ${ }^{11,14}$, a associação de nitrato de prata e nitrato de potássio na proporção de 3:1 $1^{13,15,16}$ e o hidróxido de sódio ${ }^{17-19}$.

Nos bioensaios de angiogênese em córneas que envolvem a cauterização química, a neovascularização é induzida pela inflamação, a partir da vasculatura limbar. Trata-se, pois, de um estímulo neovascular indireto ou inespecífico ${ }^{10,14}$. Por outro lado, constituem modelos de angiogênese e inflamação de baixo custo, fácil reprodução e quantificação ${ }^{15}$. Além disso, são mais vantajosos que a microbolsa com implante de pellets, quando a finalidade é estudar a neovascularização inflamatória decorrente de diversas doenças corneanas ${ }^{11}$.

Uma característica interessante dos ensaios de angiogênese em córneas é a possibilidade de múltiplas observações numa mesma unidade experimental, proporcionando, assim, o acompanhamento temporal e espacial do processo angiogênico ${ }^{7,9,10,12,13}$.

Este trabalho objetivou, então, estabelecer um modelo experimental de indução de angiogênese inflamatória em córnea de coelho, de baixo custo e fácil execução e quantificação, através da cauterização pontual com hidróxido de sódio 1 molar.

\section{Métodos}

Este estudo foi realizado de acordo com o protocolo aprovado pela Comissão de Ética em Pesquisa Animal (CEPA) da Universidade Federal do Ceará (Protocolo № 07/03).

Foram utilizados 6 coelhos brancos, de ambos os sexos, da raça Nova Zelândia, com peso variando entre 1,9 e 2,3 Kg, previamente examinados para exclusão de doenças oculares externas, os quais foram mantidos no Biotério do Laboratório de Cirurgia Experimental do Departamento de Cirurgia da Universidade Federal do Ceará, alojados em gaiolas específicas para a espécie, em condições adequadas de temperatura e umidade, com alternância dos ciclos claro/escuro a cada 12 horas e com água e alimento ad libitum.

Para a realização do procedimento de cauterização, bem como dos exames subseqüentes, os animais foram anestesiados com uma injeção intramuscular de cloridrato de cetamina (12 mg/Kg de peso) associado a cloridrato de xilazina (4 mg/Kg de peso), complementada com a instilação, no saco conjuntival, de 2 gotas do anestésico tópico cloridrato de proximetacaína $0,5 \%$. Cada animal foi observado até tornar-se alerta e, em seguida, devolvido à sua gaiola.

Uma vez anestesiado, acomodava-se o animal numa base de isopor, em decúbito lateral esquerdo e com o dorso voltado para o examinador. A seguir, colocava-se um blefarostato do tipo graduável, que propiciava um adequado afastamento das pálpebras, expondo quase toda a superfície da córnea e a região limbar superior.

Os coelhos foram, então, submetidos a uma cauterização pontual na periferia superior da córnea direita, com o auxílio de um microscópio cirúrgico com aumento de 16 vezes. Para tanto, utilizou-se uma peça circular de papel filtro com 3 mm de diâmetro, 
previamente embebida em uma solução de hidróxido de sódio (NaOH) 1 molar (M) durante 1 minuto (o excesso da solução foi retirado tocando o papel filtro numa gaze). A peça de papel filtro foi posicionada a aproximadamente $1 \mathrm{~mm}$ do limbo córneo-conjuntival, em um ponto situado às 11 horas, próximo à inserção do músculo reto superior, aí permanecendo durante
2 minutos (Figura 1A). Logo após, o olho foi irrigado com $10 \mathrm{ml}$ de solução de cloreto de sódio 0,9\%, para remoção do excesso de $\mathrm{NaOH}$. Tal técnica resultou em um sítio de cauterização circular, homogêneo e de bordas bem definidas, com cerca de 3,5 mm de diâmetro (Figura 1B).
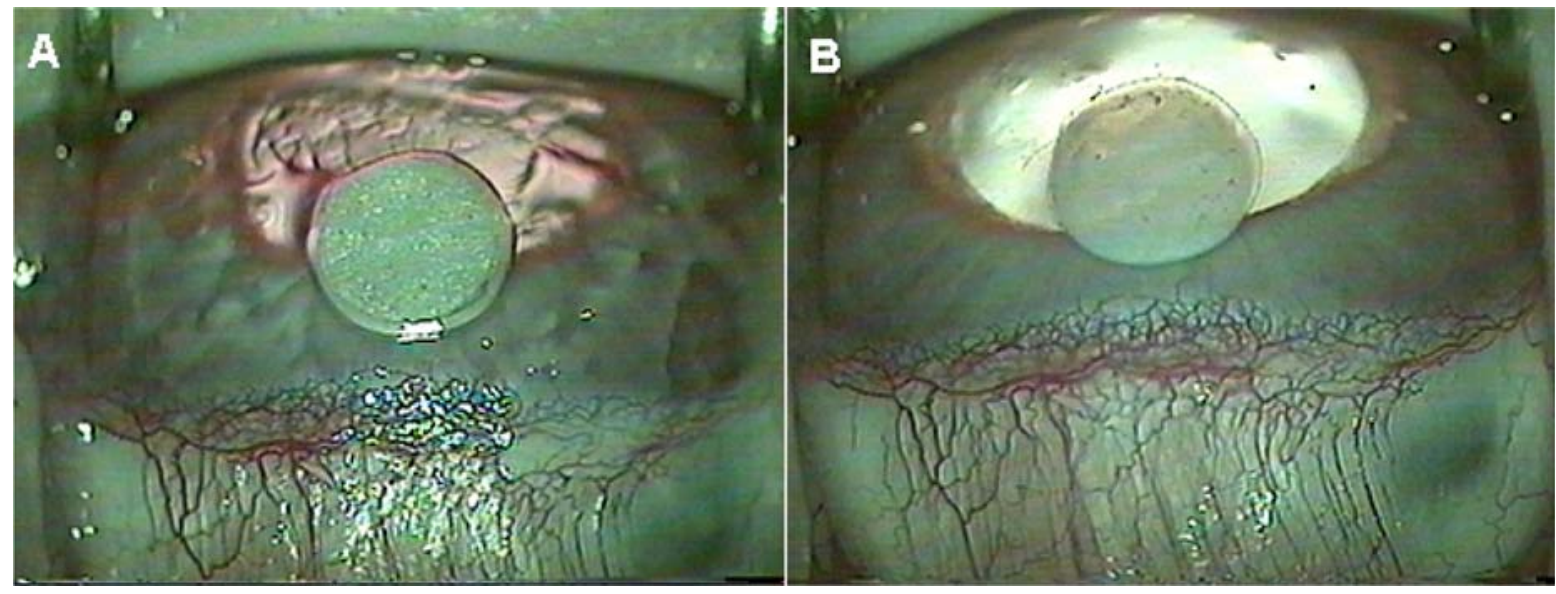

FIGURA 1 - Posicionamento da peça de papel filtro na periferia superior da córnea direita, a aproximadamente 1 mm do limbo (A); aspecto da lesão resultante (B). Magnificação de 16 vezes

Os animais foram avaliados, subseqüentemente, nos dias 3, 6, 9, 12, 15, 18 e 21, após a cauterização, ocasiões em que foram obtidos os parâmetros para o cálculo dos quantificadores de angiogênese, quais sejam: o número de neovasos presentes no extremo distal da área de angiogênese (número de vasos distais); o comprimento radial do vaso mais distante do limbo (V); a medida do segmento que une os 2 pontos do limbo córneo-conjuntival que delimitam a região de neovascularização, ou seja, a corda $(\boldsymbol{C})$ da circunferência corneana correspondente (figura 2). Durante o tempo de exposição, a córnea foi mantida hidratada com instilações freqüentes do gel líquido ocular ácido poliacrílico - um substituto da película lacrimal. As medições de $\boldsymbol{V}$ e $\boldsymbol{C}$ foram feitas com o auxílio de um compasso, sob visão microscópica, com aumento de 25 vezes. A magnificação utilizada para a contagem dos vasos distais foi de 40 vezes. As imagens foram capturadas por uma câmera de vídeo acoplada ao microscópio cirúrgico, gravadas em fitas VHS e, posteriormente, digitalizadas. Durante os procedimentos anteriormente descritos, foi acionado o filtro verde (red free) do microscópio, que proporciona um melhor contraste entre os vasos sangüíneos e as demais estruturas.

A quantificação da angiogênese foi feita de acordo com quatro métodos (Figura 2), dentre os já descritos

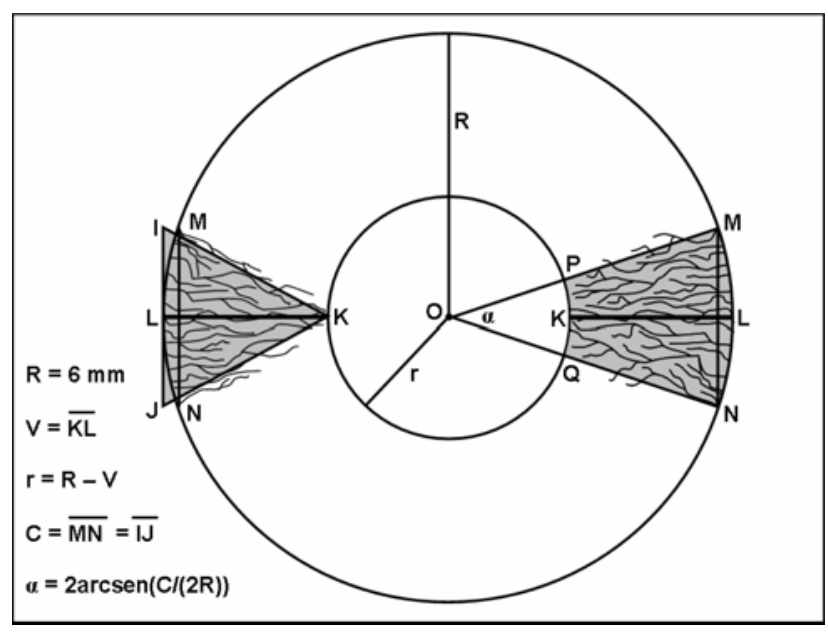

FIGURA 2 - Desenho esquemático do círculo corneano, cujo raio $(\boldsymbol{R})$ é igual a $6 \mathrm{~mm}$, mostrando a região de angiogênese, bem como os parâmetros utilizados na sua quantificação. O segmento MN corresponde à corda $(\boldsymbol{C})$ da circunferência corneana que delimita a região de neovascularização. O segmento KL corresponde ao comprimento vascular radial (V). A base do triângulo IJK é o segmento IJ (MN), que é igual a $C$, a sua altura é $V$, logo a sua área é $\boldsymbol{T}=\boldsymbol{C} . \boldsymbol{V} / 2$. A área do setor de coroa circular MNPQ $(\boldsymbol{S})$ é igual à área do setor circular MNO (á. $\left.R^{2} / 2\right)$ subtraída da área do setor circular OPQ (á. $\left.\boldsymbol{r}^{2} / 2\right)$. Sendo assim, $\boldsymbol{S}=$ $(\boldsymbol{a} / 2)\left(\boldsymbol{R}^{2}-\boldsymbol{r}^{2}\right)$, á em radianos. Substituindo á e $\boldsymbol{r}$, temos então: $\boldsymbol{S}=\operatorname{arcsen}(\boldsymbol{C} /(2 \boldsymbol{R}))\left[\boldsymbol{R}^{2}-(\boldsymbol{R}-\boldsymbol{V})^{2}\right]$ 
para mensurar a resposta neovascular em córneas de coelho. O primeiro deles consiste em determinar a distância entre a extremidade do maior vaso e o limbo, ou seja, o comprimento radial vascular $(\boldsymbol{V})^{10,13,17}$. O segundo envolve o cálculo do índice angiogênico (I), que é obtido multiplicando-se a densidade vascular pelo valor de $\boldsymbol{V}$. A densidade vascular, por sua vez, corresponde ao número de vasos distais normalizado para o intervalo de 1 a 5 , conforme os seguintes critérios: 1 (0-25 vasos), 2 (26-50 vasos), 3 (51-75 vasos), 4 (76-100 vasos), 5 (acima de 100 vasos) ${ }^{2,9}$. O terceiro método requer o cômputo da área do triângulo IJK $(\boldsymbol{T})$, que representa uma aproximação da área de neovascularização da córnea, cuja base é $\boldsymbol{C}$ e cuja altura é $\boldsymbol{V}$, de modo que: $(\boldsymbol{T}=\boldsymbol{C} . \boldsymbol{V} / 2)^{7,13}$. O quarto método estabelece que outra aproximação da medida da superfície da córnea afetada pela neovascularização pode ser obtida através do cálculo da área do setor de coroa circular $\mathbf{M N P Q}(\boldsymbol{S})^{12}$. Sendo assim, considerando que $S$ é igual à área do setor circular MNO (á. $\left.\boldsymbol{R}^{2} / 2\right)$ subtraída da área do setor circular OPQ $\left(a^{a} \cdot \boldsymbol{r}^{2} / 2\right)$, que $\boldsymbol{r}=(\boldsymbol{R}-\boldsymbol{V})$, que á $=2 \operatorname{arcsen}(\boldsymbol{C} /(2 \boldsymbol{R}))$, em radianos, e que o raio da córnea do coelho $(\boldsymbol{R})$ é aproximadamente $6 \mathrm{~mm}$, então: $\boldsymbol{S}=(\hat{\boldsymbol{a}} / 2)\left(\boldsymbol{R}^{2}-\boldsymbol{r}^{2}\right)$. Logo, substituindo $\boldsymbol{a}$ e $\boldsymbol{r}$, tem-se que: $\boldsymbol{S}=\operatorname{arcsen}(\boldsymbol{C} /(2 \boldsymbol{R}))\left[\boldsymbol{R}^{2}-(\boldsymbol{R}-\boldsymbol{V})^{2}\right]$.

Foram também calculadas as taxas médias de crescimento vascular referentes aos intervalos de 3 dias entre as avaliações, ao período entre 0 e 12 dias, ao intervalo entre o $12^{\circ}$ e o $21^{\circ}$ dia, assim como no decorrer dos 21 dias do período de observação. $\mathrm{O}$ parâmetro $\boldsymbol{V}$ (comprimento vascular radial) foi tomado como base, de modo que, para um determinado intervalo de tempo $\mathbf{t}_{1}$ a $\mathbf{t}_{2}$, a taxa média de crescimento vascular $\left(\mathbf{T}_{\mathrm{C}}\right)$ é dada por: $\mathbf{T}_{\mathrm{C}}=\left[\boldsymbol{V}\left(\mathbf{t}_{2}\right)\right.$ $\left.-\boldsymbol{V}\left(\mathbf{t}_{1}\right)\right] /\left(\mathbf{t}_{2}-\mathbf{t}_{1}\right)$. No dia zero do experimento, atribuiu-se a $\boldsymbol{V}\left(\mathbf{t}_{\mathbf{0}}\right)$ o valor zero.

Para a estatística descritiva, calcularam-se a média e o erro padrão da média. O coeficiente de correlação de Spearman foi utilizado para determinar o grau (ou a intensidade) e o sinal da correlação linear entre os quantificadores, tendo em vista que estes constituem parâmetros diferentes para mensurar um mesmo evento: a resposta angiogênica. Fixou-se em 0,05 ou $5 \%$ o nível para rejeição da hipótese de nulidade.

\section{Resultados}

Observou-se, já no $3^{\circ}$ dia após a cauterização, o crescimento de brotos vasculares em direção ao sítio de cauterização, quase alcançando a sua borda limbar, associado a dilatação dos vasos perilimbares e leve diminuição da transparência corneana nas vizinhanças da lesão. Nos dias subseqüentes, os vasos proliferaram e avançaram em direção ao estímulo, à medida que a intensidade da reação inflamatória diminuía (Figura 3). O comprimento vascular radial máximo foi de 3,5 mm.

A análise das curvas dos parâmetros de quantificação da angiogênese revelou um comportamento ascendente até o 15을 dia para a curva do índice angiogênico e até o $12^{\circ}$ dia para os demais quantificadores (Figuras 4 e 5). O índice angiogênico (I) decresceu levemente no $18^{\circ}$ dia, enquanto os demais parâmetros mantiveram-se estáveis nos dias 15 e 18. Todos os indicadores voltaram a ascender no $21^{\circ}$ dia. O valor máximo de $\boldsymbol{I}(13,7500 \pm 1,5138)$ foi atingido no $15^{\circ}$ dia. No $21^{\circ}$ dia foram observados os valores máximos de $\boldsymbol{V}(2,8750 \pm 0,2479 \mathrm{~mm}), \boldsymbol{T}$ $\left(10,6667 \pm 0,9939 \mathrm{~mm}^{2}\right)$ e $\boldsymbol{S}(17,3008 \pm 1,3024$ $\mathrm{mm}^{2}$ ). Os quatro métodos de quantificação utilizados foram, ainda, capazes de detectar mesmo variações mínimas da resposta neovascular, observadas a partir do $12^{\circ}$ dia.

A taxa média de crescimento vascular relativa aos intervalos de 3 dias alcançou o seu valor máximo entre o $3^{\circ}$ e o $6^{\circ}$ dia $(0,4167 \pm 0,0304 \mathrm{~mm} / \mathrm{dia})$, ao passo que, no período entre os dias 12 e 21, os valores diminuíram consideravelmente, variando de 0 a $0,0417 \mathrm{~mm} / \mathrm{dia}$. Ao longo dos 12 primeiros dias, a taxa média de crescimento foi $0,2292 \pm 0,0178$ $\mathrm{mm} /$ dia. Durante o intervalo compreendido entre o $12^{\circ}$ e o $21^{\circ}$ dia, foi apenas $0,0139 \pm 0,0119 \mathrm{~mm} /$ dia. A taxa média de crescimento vascular ao longo de todo o período de observação foi $0,1369 \pm 0,0118$ $\mathrm{mm} /$ dia (Tabela 1).

Esses dados sugerem que, neste modelo, a resposta neovascular se processou em duas fases claramente distintas: intenso crescimento vascular até o $12^{\circ}$ dia, seguido de uma fase de estabilidade até o final do experimento.

O valor máximo da corda $(\boldsymbol{C})$ da circunferência corneana que une as extremidades da região de neovascularização foi $8 \mathrm{~mm}$. Isto equivale ao envolvimento de um arco da circunferência corneana 


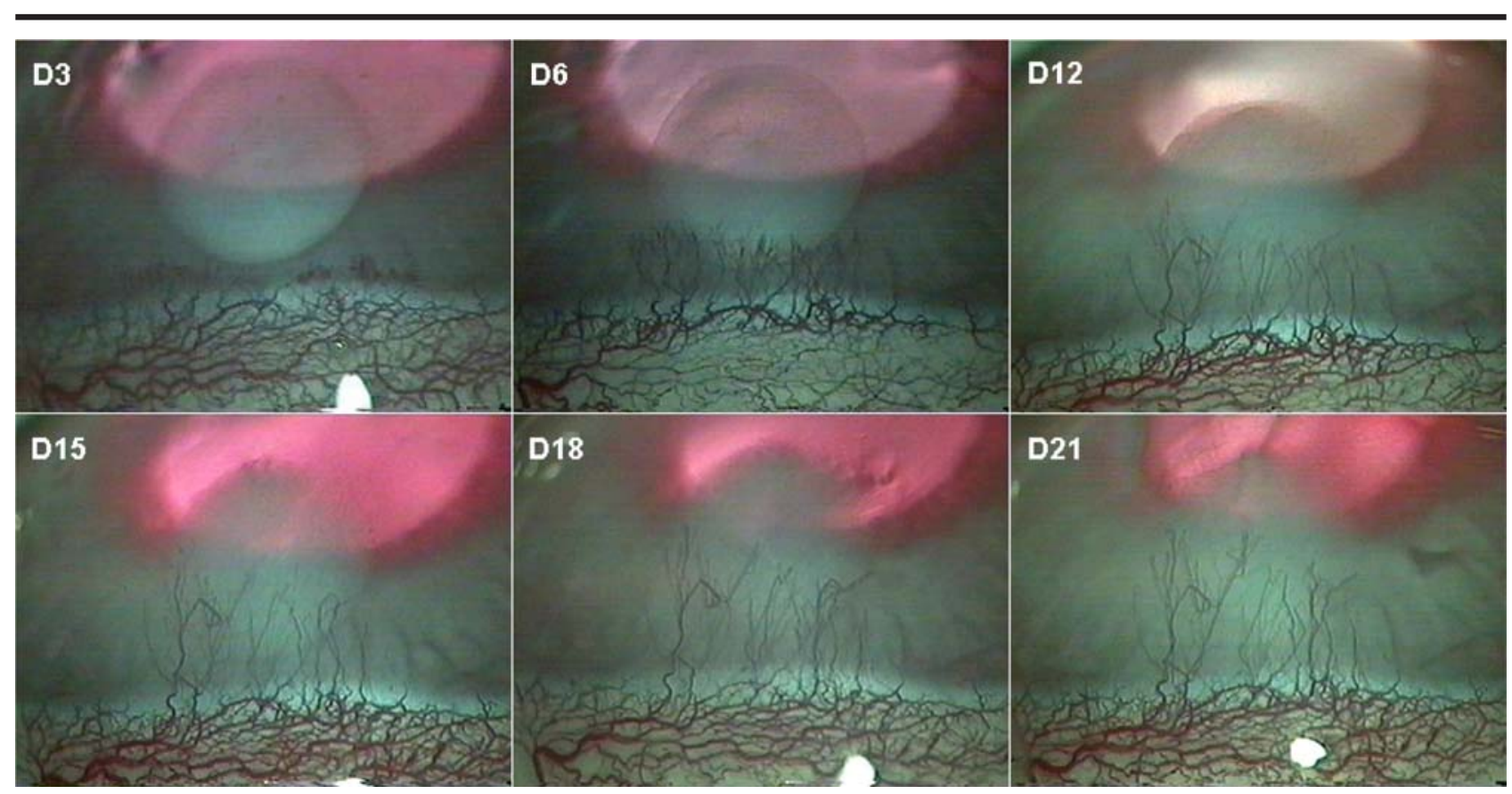

FIGURA 3 - Fotografias mostrando a progressão do processo angiogênico nos dias 3, 6, 12, 15, 18 e 21, após a cauterização. As imagens foram capturadas com a utilização do filtro verde (red free). Magnificação de 25 vezes

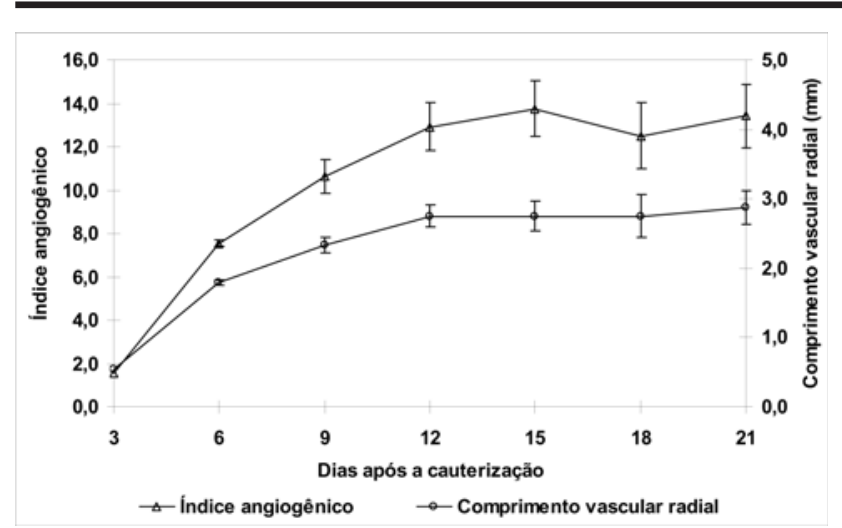

FIGURA 4 - Progressão temporal da resposta angiogênica segundo os quantificadores comprimento vascular radial e índice angiogênico. Valores expressos como média \pm erro padrão da média

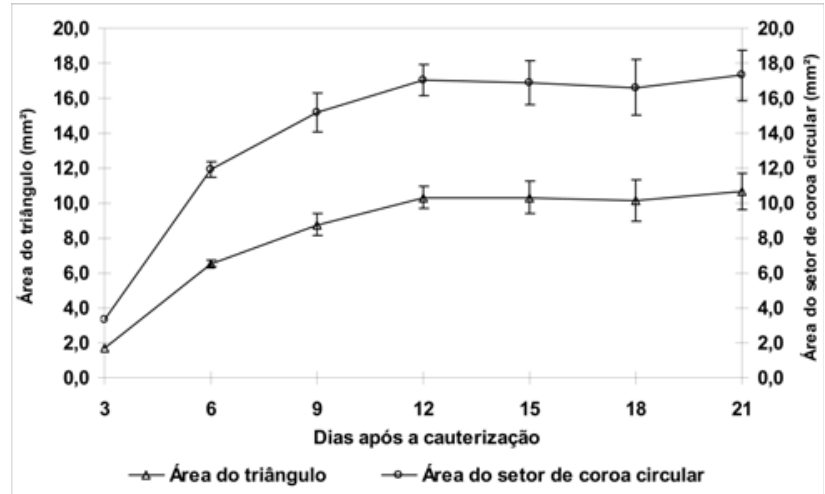

FIGURA 5 - Progressão temporal da resposta angiogênica segundo os quantificadores área do triângulo de neovascularização e área do setor de coroa circular. Valores expressos como média \pm erro padrão da média

TABELA 1 - Valores da taxa média de crescimento vascular, em mm/dia, referentes aos intervalos de 3 dias, aos períodos de 0 a 12 e de 12 a 21 dias, bem como ao longo de todo o experimento. Dados expressos como média \pm erro padrão da média

\begin{tabular}{cc} 
Intervalo (dias) & Taxa média de crescimento vascular $(\mathbf{m m} / \mathbf{d i a})$ \\
\hline $0-3$ & $0,1806 \pm 0,0139$ \\
$3-6$ & $0,4167 \pm 0,0304$ \\
$6-19$ & $0,1806 \pm 0,0398$ \\
$9-12$ & $0,1389 \pm 0,0278$ \\
$12-15$ & $0,0000 \pm 0,0430$ \\
$15-18$ & $0,0000 \pm 0,0304$ \\
$18-121$ & $0,0417 \pm 0,0469$ \\
$0-12$ & $0,2292 \pm 0,0178$ \\
$12-121$ & $0,0139 \pm 0,0119$ \\
$0-121$ & $0,1369 \pm 0,0118$
\end{tabular}


correspondente a um ângulo (á) de 84 graus.

Para verificar o comportamento de um dado quantificador em função do desempenho de outro, ao longo do experimento - ou seja, o grau da dependência linear entre os parâmetros de quantificação de angiogênese -, foi calculado o coeficiente de correlação de Spearman. Os dados revelaram uma forte correlação linear positiva, estatisticamente significante, entre os parâmetros analisados, isto é, eles tendem a aumentar ou diminuir conjuntamente (Tabela 2). Constatou-se uma correlação linear positiva perfeita entre $\boldsymbol{S}$ e $\boldsymbol{T}(\mathrm{r}=1$; $\mathrm{P}=0,0004)$. A correlação entre esses parâmetros e $\boldsymbol{V}$ foi quase perfeita $(\mathrm{r}=0,9636 ; \mathrm{P}=0,0028)$. No entanto, as correlações entre $\boldsymbol{I}$ e $\boldsymbol{V}(\mathrm{r}=0,8895 ; \mathrm{P}=$ 0,0123), $\boldsymbol{I}$ e $\boldsymbol{T}(\mathrm{r}=0,8929$; $\mathrm{P}=0,0123)$ e $\boldsymbol{I}$ e $\boldsymbol{S}$ ( $\mathrm{r}=$ $0,8929 ; \mathrm{P}=0,0123)$, apesar de fortemente positivas, foram menos intensas que as demais.

TABELA 2 - Correlação entre os quantificadores de angiogênese, verificada através do coeficiente de Spearman (r)

\begin{tabular}{cccccc}
\hline $\mathbf{V} \times \mathbf{T}$ & $\mathbf{V} \times \mathbf{S}$ & $\mathbf{V} \times \mathbf{I}$ & $\mathbf{I} \times \mathbf{T}$ & $\mathbf{I} \times \mathbf{S}$ & $\mathbf{S} \times \mathbf{T}$ \\
\hline $\mathrm{r}=0,9636$ & $\mathrm{r}=0,9636$ & $\mathrm{r}=0,8895$ & $\mathrm{r}=0,8929$ & $\mathrm{r}=0,8929$ & $\mathrm{r}=1$ \\
$\mathrm{P}=0,0028$ & $\mathrm{P}=0,0028$ & $\mathrm{P}=0,0123$ & $\mathrm{P}=0,0123$ & $\mathrm{P}=0,0123$ & $\mathrm{P}=0,0004$ \\
\hline
\end{tabular}

\section{Discussão}

Nesta pesquisa, procurou-se estabelecer um modelo de estudo de angiogênese com as seguintes características: fácil exeqüibilidade, baixo custo e que propiciasse o monitoramento temporal e espacial da resposta neovascular. Tal intento foi conseguido com a indução de angiogênese na córnea de coelho mediante a cauterização pontual com $\mathrm{NaOH} 1 \mathrm{M}$.

A cauterização alcalina da córnea constitui um modelo de inflamação e neovascularização de fácil reprodução e quantificação ${ }^{15}$. Tem sido usada para estudar o papel de leucócitos, fatores angiogênicos e mediadores da inflamação na angiogênese inflamatória ${ }^{11,14-19}$, bem como para avaliar a ação de drogas anti-inflamatórias ${ }^{13,15}$. Sendo assim, tal modelo é de grande utilidade no estudo das afecções oculares que cursam com neovascularização corneana, sejam elas de natureza inflamatória, infecciosa ou traumática ${ }^{11,15,17,19}$.

No entanto, a patogênese da neovascularização corneana ainda não está totalmente compreendida ${ }^{11}$. Em um estudo para determinar os eventos celulares que precedem a angiogênese inflamatória em córnea murina, constatou-se que o infiltrado pré-angiogênico é composto essencialmente de granulócitos e monócitos $^{14}$.

Posteriormente, em um modelo de angiogênese inflamatória em córnea de rato, foi verificado que VEGF (vascular endothelial growth factor), produzido por leucócitos que infiltram o estroma corneano - inicialmente neutrófilos e subseqüentemente monócitos/macrófagos desempenha papel fundamental na indução e manutenção da neovascularização em córneas cauterizadas e que tanto a hipóxia quanto mediadores inflamatórios aumentam a expressão de VEGF na vizinhança da lesão. VEGF, por sua vez, induz a migração e proliferação da célula endotelial ${ }^{15}$. A importância de VEGF na angiogênese inflamatória é enfatizada também em outros estudos ${ }^{16-19}$.

Recentemente, em um estudo para investigar o papel de MCP-1 (macrophage chemotactic protein-1) e da citocina pró-inflamatória interleucina1â (IL-1â) na angiogênese inflamatória em córnea de camundongo, foi sugerido que MCP-1 - liberada pelo epitélio corneano circunvizinho ao sítio de cauterização - recruta monócitos/macrófagos do sangue periférico para a córnea, onde eles liberam IL-1â, que, então, induz a neovascularização. Esta citocina pode aumentar a produção de potentes fatores angiogênicos, como VEGF, IL-8 e HGF (hepatocyte growth factor), assim como proteases e moléculas de adesão. Dessa forma, tais agentes podem ser os mediadores da neovascularização corneana induzida por IL-1â. Além disso, IL-1â e MCP-1 podem induzir diretamente neovascularização corneana, independente do recrutamento de monócitos/ macrófagos ${ }^{11}$.

A cauterização da córnea com $\mathrm{NaOH}$ tem sido usada, mormente, para induzir neovascularização inflamatória com a finalidade de reproduzir desordens oculares, como queimaduras alcalinas e síndrome de Stevens-Johnson, nas quais ocorre a perda das células 
germinativas localizadas no epitélio limbar precursoras das células do epitélio corneano e, portanto, responsáveis pela sua regeneração - e que podem evoluir com o fenômeno de "conjuntivalização" do epitélio corneano ${ }^{18,20}$. O animal utilizado geralmente é o camundongo e a técnica consiste na instilação de cerca de 2 ìl de $\mathrm{NaOH}$ 0,15 mM na superfície corneana, seguida da remoção do epitélio da córnea e da região limbar, onde se encontram as células germinativas ${ }^{17,18}$. Trata-se, portanto, de uma lesão difusa.

O papel filtro não é um instrumento de uso corriqueiro para a cauterização pontual de córneas com $\mathrm{NaOH}$. Em um modelo murino de ceratite estromal herpética, foi relatado o uso de papel filtro (peça circular de $1 \mathrm{~mm}$ de diâmetro) para cauterizar a região central da córnea com $\mathrm{NaOH}$ 0,5 normal, durante 1 minuto. O objetivo era dosar, posteriormente, VEGF em lisados de córnea e usar tais dosagens como controle positivo, para comparações com aquelas obtidas nos demais grupos do estudo ${ }^{19}$. Em outro modelo, dessa vez para queimaduras químicas oculares em coelhos, uma peça de papel filtro, em forma de meia-lua, com diâmetro de $7,5 \mathrm{~mm}$, foi utilizada para provocar uma lesão alcalina em toda a superfície corneana, bem como no limbo $^{20}$.

No presente estudo, a peça circular de papel filtro de $3 \mathrm{~mm}$ de diâmetro constituiu um instrumento simples, prático e eficaz para realização da cauterização pontual da córnea.

Um evento indesejável, quando se utiliza a cauterização química como modelo de angiogênese, é a intensidade da resposta inflamatória, que pode obscurecer os neovasos, prejudicando, sobremaneira, o procedimento de quantificação ${ }^{2}$. Às vezes, para uma adequada quantificação da neovascularização, é necessário injetar agentes que contrastem os vasos, como tinta da Índia ${ }^{15,19}$ ou compostos fluorescentes ${ }^{17,18}$. Nesses casos, a córnea necessita ser removida, preparada e montada em lâmina (flatmounted cornea), de modo que uma única avaliação é feita, requerendo, assim, grande número de animais.

Neste trabalho, pretendeu-se estabelecer um modelo de cauterização pontual, onde a neovascularização se restringisse à região do estímulo e a reação inflamatória não dificultasse a quantificação; e que, além disso, permitisse avaliações sucessivas no mesmo animal. De fato, a técnica empregada resultou em um sítio de cauterização homogêneo e bem delimitado, restrito à área de aplicação da peça de papel filtro e sem comprometimento da região limbar. Isto possibilitou a indução de angiogênese localizada, não envolvendo grande extensão da circunferência corneana - o que dificultaria a quantificação dos neovasos - atingindo um ângulo máximo de aproximadamente $84^{\circ}$. Comparativamente, um ângulo de $120^{\circ}$, portanto significativamente maior, foi observado em córneas de coelho cauterizadas com nitrato de prata/nitrato de potássio ${ }^{13}$. Além disso, a reação inflamatória foi pouco proeminente, não tendo sido empecilho para a observação e quantificação dos neovasos, os quais podiam ser vistos, sem dificuldade, mesmo na região cauterizada, dispensando, assim, o uso de meios de contraste. Foi mais intensa no $3^{\circ}$ dia e diminuiu progressivamente ao longo do experimento. Em alguns animais, no final do estudo, a transparência corneana, no sítio de cauterização, estava praticamente restaurada.

Analisando os gráficos dos quantificadores de angiogênese pôde-se inferir que a progressão temporal da resposta angiogênica seguiu um padrão bifásico: uma fase ascendente, quase linear, até o $12^{\circ}$ dia, seguida de uma fase de estabilidade, que perdurou até o fim do experimento. Esse comportamento também se refletiu na taxa média de crescimento vascular, cujo valor no intervalo de $0 \mathrm{a}$ 12 dias $(0,2292 \pm 0,0178 \mathrm{~mm} /$ dia $)$ foi 16 vezes maior do aquele referente ao período entre o $12^{\circ}$ e o $21^{\circ}$ dia $(0,0139 \pm 0,0119 \mathrm{~mm} /$ dia $)$. No intervalo entre $o$ $3^{\circ}$ e o $6^{\circ}$ dia a taxa média de crescimento atingiu o seu valor máximo. Tal padrão bifásico se correlaciona com as fases proliferativa e regressiva, observadas em um modelo de neovascularização inflamatória em córneas de ratos ${ }^{15}$. A primeira se caracteriza por intensa proliferação vascular. A densidade vascular é alta, observam-se inúmeros brotos e a taxa de crescimento vascular alcança seu valor máximo. A fase regressiva se caracteriza pela maturação vascular. Os neovasos se alongam, diminuem as ramificações e a taxa de crescimento vascular se estabiliza.

Os dados expostos no parágrafo anterior demostram que o período de observação adotado, 21 dias, foi adequado, uma vez que propiciou o acompanhamento temporal do processo angiogênico, denotado pela clara distinção entre as fases de proliferação e maturação. De fato, os períodos de 
observação relatados em estudos que utilizam ensaios de angiogênese em córneas de coelho não costumam extrapolar os 21 dias, geralmente são menores: doze $^{12}$, quinze ${ }^{2}$, dezoito ${ }^{17}$, vinte e um dias ${ }^{7}$.

A associação entre os quatro quantificadores de angiogênese foi avaliada através do coeficiente de correlação de Spearman. Constatou-se uma forte correlação linear positiva, estatisticamente significante, entre eles. Isto demonstra que, apesar de constituírem abordagens diferentes para mensurar a resposta angiogênica, apresentam um comportamento temporal similar, ou seja, o modelo proposto não leva a resultados discrepantes quando avaliado por métodos distintos. Em outras palavras, os quatro métodos quantificaram a resposta neovascular de forma semelhante. É interessante notar que a perfeita correlação linear entre $\boldsymbol{T}$ e $\boldsymbol{S}$ decorreu, decerto, do fato de ambos os parâmetros serem funções das mesmas variáveis: $\boldsymbol{V}$ e $\boldsymbol{C}$. Por outro lado, a intensidade da correlação entre $\boldsymbol{I}$ e os outros quantificadores foi menos acentuada que a das demais. Certamente, isto foi conseqüência da influência da densidade vascular (número de vasos distais normalizado para o intervalo de 1 a 5) no cálculo de $\boldsymbol{I}$.

A técnica de cauterização alcalina pontual utilizada neste trabalho foi capaz de induzir e manter angiogênese corneana durante todo o período de observação, como atestam os quantificadores, com uma taxa média de crescimento vascular de 0,1369 $\pm 0,0118 \mathrm{~mm} /$ dia. Além disso, o modelo possibilitou o monitoramento espacial e temporal do processo angiogênico in vivo. Assim sendo, este ensaio requer um número menor de animais ${ }^{-}$quando comparado com estudos semelhantes, onde a córnea necessite ser removida ${ }^{-}$, uma vez que permite múltiplas observações numa mesma unidade experimental.

Neste estudo, descreveu-se um modelo experimental de angiogênese onde a neovascularização é induzida pela inflamação que se instala, tratando-se, pois, de um estímulo neovascular inespecífico $^{10,14}$. Difere, portanto, dos ensaios com implante de pellets de liberação lenta contendo um fator pró-angiogênico, onde a resposta angiogênica decorre da estimulação direta pelo fator utilizado, isto é, de um estímulo específico ${ }^{2,10}$. Assim sendo, o modelo proposto destina-se, essencialmente, ao rastreamento de drogas com atividade antiangiogênica. Poderá ainda ser útil para verificar o papel de células inflamatórias e seus produtos no processo angiogênico.

\section{Conclusão}

A cauterização pontual da córnea de coelho com $\mathrm{NaOH} 1 \mathrm{M}$ induz e mantém angiogênese corneana localizada e possibilita o monitoramento temporal e espacial da resposta angiogênica in vivo, constituindo, assim, um modelo de estudo de angiogênese de baixo custo e fácil reprodução, destinado, mormente, ao rastreamento de drogas com atividade antiangiogênica.

\section{Referências}

1. Papetti M, Herman IM. Mechanisms of normal and tumorderived angiogenesis. Am J Physiol Cell Physiol. 2002;282:C947-70.

2. González RP, Leyva A, Melo RAB, Moreira RDM, Pessoa C, Farias RF, Moraes MO. Método para o estudo in vivo da angiogênese: indução de neovascularização na córnea de coelho. Acta Cir Bras. 2000;15:168-73.

3. Risau W. Mechanisms of angiogenesis. Nature. 1997;386:671-4.

4. Folkman J. Clinical applications of research on angiogenesis. N Engl J Med. 1995;333:1757-63.

5. Folkman J, Shing Y. Angiogenesis. J Biol Chem. 1992;267:10931-4.

6. Pepper MS. Role of the matrix metalloproteinase and plasminogen activator-plasmin systems in angiogenesis. Arterioscler Thromb Vasc Biol. 2001;21:1104-17.

7. BenEzra D, Griffin BW, Maftzir G, Sharif NA, Clark AF. Topical formulations of novel angiostatic steroids inhibit rabbit corneal neovascularization. Invest Ophthalmol Vis Sci. 1997;38:1954-62.

8. Auerbach R, Lewis R, Shinners B, Kubai L, Akhtar N. Angiogenesis assay: a critical overview. Clin Chem. 2003;49:32-40.

9. Ziche M. Corneal assays for angiogenesis. In: Murray JC. Angiogenesis protocols. New Jersey: Humana Press; 2001. p.131-42.

10. Kenyon BM, Voest EE, Chen CC, Flynn E, Folkman J, D'Amato RJ. A model of angiogenesis in the mouse cornea. Invest Ophthalmol Vis Sci. 1996;37:1625-32.

11. Yoshida S, Yoshida A, Matsui H, Takada Y, Ishibashi T. Involvement of macrophage chemotactic protein-1 and interleukin-1â during inflammatory but not basic fibroblast growth factor-depedent neovascularization in the mouse cornea. Lab Invest. 2003;83:927-38.

12. D’Amato RJ, Loughnan MS, Flynn E, Folkman J. Thalidomide is an inhibitor of angiogenesis. Proc Natl Acad Sci USA. 1994;91:4082-5.

13. Conrad TM, Chandler DB, Corless JM, Klintworth GK. In vivo measurement of corneal angiogenesis with video data acquisition and computerized image analisys. Lab 
Invest. 1994;70:426-34.

14. Sunderkötter C, Beil W, Roth J, Sorg C. Cellular events associated with inflammatory angiogenesis in the mouse cornea. Am J Pathol. 1991;138:931-9.

15. Edelman JL, Castro MR, Wen Y. Correlation of VEGF expression by leukocytes with the growth and regression of blood vessels in the rat cornea. Invest Ophthalmol Vis Sci. 1999;40:1112-23.

16. Zhang H, Li C, Baciu PC. Expression of integrins and MMPs during alkaline-burn-induced corneal angiogenesis. Invest Ophthalmol Vis Sci. 2002;43:955-62.

17. Joussen AM, Beecken WB, Moromizato Y, Schwartz A, Kirchhof B, Poulaki V. Inhibition of inflammatory corneal angiogenesis by TNP-470. Invest Ophthalmol Vis Sci. 2001;42:2510-16
18. Moromizato Y, Stechschulte S, Miyamoto K, Murata T, Tsujikawa A, Joussen AM, Adamis AP. CD18 and ICAM1-dependent corneal neovascularization and inflammation after limbal injury. Am J Pathol. 2000;157:1277-81.

19. Zheng M, Deshpande S, Lee S, Ferrara N, Rouse BT. Contribution of vascular endothelial growth factor in the neovascularization process during the pathogenesis of herpetic stromal keratitis. J Virol. 2001;75:9828-35.

20. Rymer S, Burnier M, Marinho D, Kwitko S, Belfort Junior $\mathrm{R}$, Rohe D. Transplante autólogo de limbo conjuntival e de limbo córneo-conjuntival no tratamento das queimaduras químicas oculares em coelhos. Arq Bras Oftalmol. 2002;65:161-70.
Correspondência:

Manoel Odorico de Moraes Filho

Departamento de Fisiologia e Farmacologia

Rua Cel. Nunes de Melo, 1127

Caixa Postal 3157

60431-970 Fortaleza-CE

Tel: (85)288-83.38

odorico@ufc.br
Conflito de interesse: nenhum

Fonte de financiamento: nenhuma

Recebimento: 13/10/2004

Revisão: 25/11/2004

Aprovação: 28/12/2004

\section{Como citar este artigo:}

Fechine-Jamacaru FV, Fechine Júnior JU, Moraes Filho MO. Modelo de angiogênese inflamatória em córnea de coelho induzida pela cauterização alcalina pontual. Acta Cir Bras. [serial online] 2005 Jan-Fev;20(1). Disponível em URL: http://www.scielo.br/acb

*Figuras coloridas disponíveis em www.scielo.br/acb 